\title{
Sports journalism and cultural authority in the digital age
}

\author{
Simon McEnnis
}

Sports journalists are experiencing transformations to the bases of their cultural authority in the twenty-first century. Sports journalism moved towards gossip and sensationalism in the 1960 s as a result of the displacement of its reportage of sports events by radio and television (Whannel 2002). This shift led to an increasing demand on access to sources inside professional sport for stories that would often be aggressively pursued (Boyle 2006). Sports journalism therefore became reliant on its place within the sport-media production complex to legitimize its dominant position as the constructors of meaning and context around sport (Wenner 1989). The sport-media production complex is defined as a series of inter-locking, networked power relationships between media, sponsors, clubs, leagues and governing bodies leading to the manufacture of sport as a commodity.

Sports journalists consider access to the professional sports environment to be vital to their occupational distinctiveness in the dilution into one of the many voices in public communication in the digital age (Boyle 2013). However, sports journalists' connections with athletes and coaches/managers have become more distant in a heavily commodified and commercialized professional sports environment controlled by media managers (Sherwood, Nicholson and Marjoribanks 2016a, 2016b). Sports journalists have seen their privileged access diminished due to the economic power of the broadcast media, while sports clubs are becoming increasingly interested in being their own content providers as part of wider business strategies to generate revenue through more comprehensive media engagement from audiences/consumers (Hutchins and Rowe 2012).

Further, news organizations incur considerable expense and devote significant resources to financing globe-trotting journalists since the internationalization of sport at the beginning of the $20^{\text {th }}$ century. Routines initially involved long ship journeys to cover overseas cricket tours and have since intensified with the rise of global mega-events such as the Olympics and the football World Cup (Boyle and Haynes 2009). Costly access arrangements are now under increasing scrutiny as media businesses struggle to accumulate advertising revenues on digital platforms comparable to the pre-internet newspaper era.

This essay explores how the foundations of sports journalism's cultural authority are destabilized due to the professional need for access encountering uncertainty in both its external (sport-media production complex) and internal (news organization) environments. Sports journalism as an occupational group is identified with the print/newspaper tradition despite the emergence of broadcast and digital media (Boyle 2006). Newspaper journalists are considered to be the 'genuine craftsmen' (Meltzer 2009: 61) within the media industries even though they share a wider community of practice with broadcast journalists (Hutchins and Boyle 2016). The broadcast media actually confer prestige upon the print tradition by using newspaper sports journalists as on-air guests or pundits on radio and television. 
To inform this essay, I use both my industry knowledge as a sports journalist with a U.K. national newspaper (The Sun) for 10 years, and reflections on previous research interviews with 27 U.K. sports journalists over a five-year period (McEnnis 2013, 2015, 2016). I also synthesize key recent findings in sports media scholarship relevant to an analysis of cultural authority in sports journalism. The essay will focus on football to reflect the Premier League's domination of sports coverage in the U.K media.

The term digital age is used to define how sports communication has become increasingly focused on online channels. The digital age started with the advent of the Web 2.0 era of the Internet which, among other things, enabled users to be content producers as well as consumers (O'Reilly 2007; Sherwood and Nicholson 2012). Exactly when this era began is unclear, but a consensus situates it at around late 2003 or early 2004 (O'Reilly 2007; Cormode and Krishnamurthy 2008). This chapter will start by exploring how sports journalism established cultural authority before identifying recent transformations to its conditions. The essay will conclude by considering what these shifts potentially mean for sports journalism's authoritative voice in moving forward.

\section{EXPLORING CULTURAL AUTHORITY IN SPORTS JOURNALISM}

Recent sociological studies into journalism professionalism have tended to focus on why the professional project is important to journalism rather than whether the occupation can justifiably call itself a profession (Aldridge and Evetts 2003; Anderson 2008; Anderson and Schudson 2009; Lewis 2012; Waisbord 2013). Professionalism is a particularly important discourse to journalism in the digital age as journalists conduct boundary work to protect the occupation as its norms and practices become increasingly porous (Aldridge and Evetts 2003; Waisbord 2013). Cultural authority is a manifestation of professional power that can be defined as a 'form of domination considered largely legitimate by those who both exercise and are subject to it' (Anderson 2008: 250). These discourses are generally based around how journalists construct their status as experts and articulate their expertise (Lewis 2012). This essay's position is that sports journalism's status as experts and narratives around expertise are situated within their narrow source environment of the sports-media production complex.

My previous research has found that sports journalists equate consistent attendance at sports events with the accumulation of journalistic expertise (McEnnis 2013, 2015). Such narratives are more prevalent than those around professional training and education. Further, sports journalists' discourses around expertise are located within the sport-media production complex (e.g. cultivation of sources, ability to analyse and communicate events, and interviewing prowess). My past findings are conducive to a culturalist framework of analysis that Barbie Zelizer (1992) developed in her seminal work Covering the Body, which used a case study of the John F Kennedy assassination to explore how journalists promoted themselves as cultural authorities. Here, Zelizer argues expert status and expertise are discursive constructions and that authority arises from boundary work that is rooted in journalistic narratives. To reinforce this point, Aldridge and Evetts (2003: 560) note that journalism is 'an intensely reflexive occupation which constantly talks to and about itself'. I will now discuss how sports journalism constructs its expert status and develops a narrative of expertise using a combination of professional ideology and occupational mythology.

Sports journalism is closely aligned with the discourses of wider news culture in the U.K. because it has historically been part of the mainstream media and failed to evolve as a specialist press (Boyle and Haynes 2009). Sports journalists therefore share moral authority 
with the wider newsroom that derives from a professional ideology of objectivity, autonomy, immediacy, ethics and public service (Deuze 2005). Objectivity alludes to the ability of reporters to be impartial and disinterested in their reporting. Sports journalists are expected to be autonomous from both internal forces, such as the politics and motivations of newspaper proprietors, and external forces including the source environment and advertisers. Immediacy can be defined by the need to publish as soon as possible to beat the competition to the story, while ethics refers to the need for morally responsible conduct. Finally, journalists are accountable to the public and are expected to operate on behalf of society's best interests.

This belief system provides the justification for privileged access to the sports event. It also helps to mask the ways that journalism serves to reinforce power structures sport through promotional coverage and how newspapers focus on hyper-commercialized sports to the exclusion of others (Lowes 1999; McChesney 2008). Press facilities at stadiums/arenas are symbolic of the sports journalist's public service function that involves discourses around acting as the eyes and ears of the public. The press box is also an environment that adheres to journalism's values in that any display of partisanship, such as cheering or celebrating, is considered inappropriate conduct (Steen 2007). The journalist occupies a special place at the sports event - such as free entry, hospitality and press conferences/briefings - based on this narrative. Sports journalists are thus in a position to be 'an important source of information, gossip and insight for the sports fan' (Boyle and Haynes 2009: 164) despite their reputation for shying away from more serious, investigative journalism (Rowe 2004; Boyle 2006; Sugden and Tomlinson 2007).

Sports journalism has also constructed a highly romanticized narrative around itself that has greatly contributed to its cultural standing. Aldridge and Evetts (2003: 560) describe the occupational mythology of news journalism as having an 'unusually elaborate and frequently paraded occupational belief system in which rugged individualism, frightening but charismatic editors, and outrageous behaviour are central themes'. Sports journalism has constructed its own specialist brand of occupational mythology. Sports journalism is organized using the beat system, which involves reporters being assigned to certain sports or, in the case of football, geographical areas, and guarantees a steady and consistent flow of content (Nicholson, Kerr and Sherwood 2015).

Sports journalism's status as experts is validated by membership of the press pack. The press pack, a grouping of sports journalists working for rival media organizations in the same arenas, is a product of the beat system. These journalists exhibit a curious mix of competition and camaraderie, and they work together in press conferences and media briefings to try and extract what they consider to be the most newsworthy information from interviewees (Sugden and Tomlinson 2007). The press pack will also often share transcription duties while closing ranks and pooling information if one reporter should come across an exclusive story. Sugden and Tomlinson (2007: 560) note the intention of the press pack here is to 'fend off the wrath of their editors who will want to know why their reporters were beaten to a story by their rival'. The sports reporter's ability to 'play the game' is important to their integration. The press pack is a prevalent feature in sports journalism's occupational mythology and plays out in other forms of media such as Sky Sports' Sunday Supplement television programme, which involves sports journalists from different national newspapers discuss topical talking points in football while seated around a breakfast table, and numerous podcasts (e.g. Guardian Football Weekly and BT Sports' Football Writers' Podcast). 
In the mid-twentieth century, newspapers started making greater demands on sports clubs and organizations to generate knowledge relating to gossip and chatter due to the displacement of their core function of describing the event by the emerging technologies of radio and television (Whannel 2002). The growth of a popular, tabloid press accentuated this shift of direction. Sports journalists started to develop notions of expertise built around building trustworthy relationships with sources and extracting revelatory information. Journalists defined both cultural and economic worth by their association with the top athletes and coaches of the day. Sports journalists' access also makes them constructors of meaning and understanding around sport (Rowe 2004, Boyle, Rowe and Whannel 2009) and architects of sports stars and heroes (Whannel 2002).

This occupational mythology can also be evidenced in the wider cultural production beyond newspapers with sports journalists serving as ghost writers of sportspeople's autobiographies while producing their own books based on their privileged accreditation. The newspaper as a medium indicates both permanence and longevity that creates a connection with other print-based literary forms such as novels. For instance, a selection of writing from the late Daily Mail sports journalist lan Wooldridge (2007) is called Searching for Heroes. Wooldridge is featured on the front-cover photograph sitting on a child's bed with Manchester United football legend George Best while a back cover photograph has Wooldridge arm wrestling with former world heavyweight boxing champion Mike Tyson. Another example here would be Providing You Don't Kiss Me: 20 Years with Brian Clough (Hamilton, 2007), which is a chronicle of a journalist-source relationship between Nottingham Evening Post reporter Duncan Hamilton and Clough, former manager of Nottingham Forest. The book won the prestigious William Hill Sports Book of the Year in 2007.

Sports journalism in the U.K. has always traded heavily on a cultural heritage that Boyle (2006: 31) describes as 'the shadow cast by the historical traditions and legacy of previous forms of sports journalism and sportswriters'. Contemporary sports writers are sustaining this mythology. Simon Barnes invokes the journalist's role as key cultural narrator in his book The Meaning of Sport (2006) written while he was The Times chief sports writer. Guardian and Observer sports journalist Daniel Taylor (2008) uses his positionality as beat reporter to write about behind-the-scenes insights into the former Manchester United manager Alex Ferguson called This is the One: Alex Ferguson: The Uncut Story of a Football Genius. Sports journalism further confers prestige and status upon itself through the award ceremonies of professional body, the Sports Journalists' Association (SJA).

\section{TRANSFORMATIONS TO THE BASES OF CULTURAL AUTHORITY}

Sports journalists, in common with the wider newsroom, are experiencing a struggle for occupational distinctiveness because of the loss of control over communication channels in the Web 2.0 era. In the twentieth century, newspapers monopolized the production of sports texts because the means of production were a scarcity (Hutchins and Rowe 2009). Now, agencies from outside the occupational group, such as bloggers, have adopted sports journalism's norms and routines (Dart 2009; Hutchins and Mikosza 2010; McCarthy 2012, 2014; McEnnis 2016). Previous studies have found sports journalists consider their privileged access to the professional sports environment to be vital for providing specialized knowledge that is inaccessible to those outside the occupation (McEnnis 2013, 2016). So it can be argued that sports journalists have never had a greater need for accreditation to safeguard their occupational boundaries. 
However, in the twenty-first century, economic factors are impacting heavily on the bases to sports journalism's cultural authority. Print journalists have become marginalized from a highly commodified and commercialized professional sports environment defined by economic power. Broadcast sports journalists working for pay-TV channels benefit from privileged access to athletes, coaches and managers written into the contracts of multibillion pound right deals. Print sports journalists are also lower priority than the global broadcast network around football in particular, such as the IMG-owned Premier League Productions, which produces and provides content for overseas rights holders.

Source relations between journalists and sport insiders have been further disrupted by the rise of the promotional age and the close guarding of access from public relations managers (Boyle 2006; Sugden and Tomlinson 2007; Sherwood, Nicholson and Marjoribanks 2016a, 2016b). Although the Premier League came into existence in 1992, the exponential growth of live TV rights in the 2000s and therefore income to clubs has meant that brand reputation has become increasingly important. As a result, media relations are now defined by carefully orchestrated and tightly controlled interactions between journalists and athletes/coaches. It has also meant sports journalists' primary concern is now building relationships with media managers (Sherwood, Nicholson and Marjoribanks 2016a) rather than athletes and coaches. One sports journalist that I interviewed recalled a football manager agreeing to an interview in person only for a media manager to reverse this arrangement and express outrage at the request not going through him.

Sports journalists cover carefully stage managed press conferences in which certain questions - usually the most interesting and pertinent - are ruled off limits by communications managers. Reporters are threatened either with bans or the press conference being cut short - both with the intention of starving them of an important information flow for stories. Broadcast rights holders tend to lead the questioning which signposts their prioritization over print journalists in these environments. Post-event interviews take place in mixed zones described as the 'carefully rationed spaces wherein the media can briefly interact with players and coaches' (Sugden and Tomlinson 2007: 51). The more fluid, informal spaces around source relations have all but disappeared. During my own experiences as a sports journalist, I recall approaching Ipswich Town midfielder Jim Magilton in the Portman Road car park after a match for an interview at a time when the club were in the Premier League at the turn of the century. Such a scenario is impossible to imagine now. Tomlinson (2016) warns against romanticizing the past as press bans and attempts by clubs to influence media coverage existed in the 1960s. However, it is clear that sports journalists enjoyed greater access to sportspeople in the past. Boyle (2006: 43) notes that in the 1960 s 'top players would happily go for a drink with members of the press pack' before access to sports stars started to change in the 1980s.

Journalistic access is further disrupted by the fact that sports organizations have their own TV and digital channels publishing news, interviews and features. Traditional sources are now media themselves and are therefore in competition and conflict with the press. This often means that the print media are granted access to the more inconsequential and less interesting performers on the sporting field. There are still, however, benefits to professional sports clubs and organizations of granting access to the print media. Sports journalism's occupational belief system of independence and neutrality is more appealing to the public imagination than the impression of bias and myopia on club websites. Sports journalism implies rigorous professional standards are applied to source material. Clubs and organizations can therefore benefit from the impression that knowledge generated within the sport-media production complex has been subject to checks and balances before being 
disseminated to the public by the mainstream media. However, these potential gains are being significantly outweighed by the global business strategies of sports clubs that dictate information and content is a valuable commodity to be bought and sold (Hutchins and Rowe 2012).

Nevertheless, the print media continue to operate in a tense and unpredictable source environment that has led to unstable access arrangements. One key incident involved only one newspaper (The Mirror) being admitted to the unveiling of new Newcastle United manager Steve McClaren alongside the live TV rights holder, Sky Sports. The excluded national newspapers considered this move to have a chilling effect on press freedom but it came a year after Newcastle had struck a similar exclusive arrangement with The Sun newspaper, which The Mirror had heavily criticized (Turvill 2015). Soon after this incident, newspaper organizations combined with national news agencies, a formation called the News Media Coalition (NMC), to sign a three-year deal with the Premier League and Football League to attempt to safeguard access arrangements (Sweney 2015). An official press release from the NMC points to a balancing act between the competing business interests of both journalists and sources by stating: 'the agreement strikes the right balance between the legitimate business of editorial-based press, publishing and distribution on one hand and the leagues' and clubs' own services on the other' (News Media Coalition 2015). However, this deal also served as a form of protectionism around access being the domain of mainstream media organizations while involving the exclusion of non-mainstream agencies.

These external challenges to sports journalism are further compounded by the internal problems of news organizations struggling to make money on digital platforms. Marketdriven factors are increasingly overshadowing professional principles such as objectivity, public service, ethics and autonomy. News companies vie for scarce economic resources in the digital environment that has led to heavily reductive content that is judged by the number of eyeballs in web clicks and page impressions that it generates rather than the quality of journalism, a process that is commonly known as clickbait. Precise metrics mean that the commercial emphasis is now on individual sports stories that attract a mass readership on their own right rather than a collective of articles that piece together a cumulative general readership. The latter applied to the traditional newspaper model in which a range of sports and all 92 league football clubs are covered under the rationale that a general readership is developed by providing something for everyone.

Digital business models favour football clubs with significant fan bases as these represent mass global readerships and cost-efficient production routines. A tabloid sports journalist told me in a research interview that he was aware of a digital sports desk asking a reporter to only file transfer rumour stories concerning five of England's biggest clubs of Chelsea, Manchester United, Arsenal, Liverpool and Tottenham and the rest of Europe's big three of Barcelona, Bayern Munich and Real Madrid from the 2016 European Championships. He said: "It's the click-through rate. You could have written some beautiful stuff online but some bloke in south-east Asia who has got two minutes to click on a story that says 'Manchester United are interested in such-and-such', may or may not be true but it has got a quarter-of-a-million views."

It is therefore easy to see the potential implications for the resourcing of sports journalism's beat routines and the expense of time, travel and accommodation across a global sports environment. The chilling effect has already caused shudders at local level as it was reported in 2015 that Newsquest North London, a local newspaper group, decided it was not cost effective to send its sports reporter to away games involving Barnet because the number of 
clicks on the stories could not justify the resourcing of a staff member, opting to outsource instead (Sports Journalists' Association 2015). I stated earlier that sports journalists' construction of their status as experts depended on their constant attendance of sports events and engagement with the professional sports environment. Such a development therefore unhinges this narrative.

\section{CONCLUSION: SPORTS JOURNALISM AND CULTURAL AUTHORITY...WHAT NEXT?}

Sports journalists face challenges in maintaining their cultural authority in the digital age due to transformations in its conditions. Journalists are increasingly dependent on commercial sports yet are subject to limited, poor quality access with no guarantee of accreditation. Sports journalism's justification for privileged access to commercial sports through its professional ideology seems inconsequential compared to the vast and naked economic power of broadcast media organizations paying billions of pounds for live TV rights. As Banagan (2011: 165) notes, 'for the immediate future economics will prevail over objectivity or public service'.

Quality of access is now defined by financial transactions rather than journalistic expertise of cultivating contacts and building trust with key sports personnel. Sports journalists' claims to expert status and expertise have never been more disconnected from their lived experience in the twenty-first century. Sports journalism's cultural authority is vulnerable to delegitimization. Sports journalism's problems are exacerbated by its fixation and dependence on official sources to both generate and validate stories (Lowes 1999; McChesney 2008).

Newspaper organizations lack the financial power should they ever lose free access to the sport-media production complex and start having to pay their way like broadcast rights holders. Such an outcome will surely benefit cross-ownership models such as Rupert Murdoch owning News UK, publishers of The Sun, The Times and Sunday Times newspapers, as well as Sky Sports, the principal TV rights holders of Premier League football. We may have already seen the genesis of such a development in the way that this monopoly uses collective bargaining power to secure the digital in-game content and highlights rights to the Premier League for three years from the 2016/17 season. Sky Sports claimed it had 'entered into an exclusive distribution partnership with News UK that will also see clips being made available across The Sunday Times, The Times and The Sun digital services' (Sky Sports 2015). Outside of the Murdoch empire, national newspaper organizations would have to strike unethical sponsorship arrangements to subsidize rights deals. These economic arrangements would make newspaper and broadcast sports journalism difficult to distinguish.

The future of sports journalism's cultural authority may be located in how it makes use of unofficial sources outside the commercialized sport environment. A good example of an effective step in this direction is The Guardian's Daniel Taylor working with whistleblower Andy Woodward, a retired former Crewe Alexandra footballer subjected to sexual abuse by a coach. Taylor's story won both News Reporter and Sports Reporter at the Society of Editors' Press Awards in March 2017.Sports journalism could also reach out beyond the occupational group to evolve its bases of cultural authority. Anderson (2008: 262) has pointed to the potential of a 'networked authority' of collaborative, decentralized projects. In 2016, Richard Hunt, of the Charlton Athletic Supporters Trust and supported by a coalition of 15 supporters' groups, demonstrated impressive journalistic determination and nous in exposing the full details of West Ham United's deal to rent the Olympic Stadium in London 
as its permanent home (Hytner 2016). Hunt submitted a successful Freedom of Information (Fol) request to the London Legacy Development Corporation (LLDC), the public organization charged with overseeing the London 2012 Olympic Games legacy. However, Hunt did not achieve this feat without struggle - he was forced to appear in tribunal as the LLDC appealed against the Information Commissioner's original decision in favour of disclosure. A further possibility is that sports journalists could move into more collaborative, crowdsourced spheres of journalism but they would need to overcome the self-perception that inside access and vast experience of attending sports events make them more knowledgeable than the average fan (Sherwood and Nicholson 2012; McEnnis 2013, 2016).

Other questions and possibilities remain for sports journalism's cultural authority. Aldridge and Evetts (2003) note that journalists embellish their occupational mythology as news work becomes increasingly constrained and routine. Does this theory mean sports journalism will rely further on its cultural heritage and nostalgic recollections of a golden age as it becomes increasingly alienated from the sports-media production complex? Will sports journalism only be concerned with access to clubs that generate the most web traffic? Will broadcast sports journalists eclipse print sports journalism as the authoritative voice of sport? Will newspaper organizations continue to be granted free access to the professional sports environment? If so, what will this mean for the plurality of the media and/or the importance of concentrated, cross-ownership models? Will these spaces continue to be dominated by mainstream media or will non-mainstream organizations and bloggers be increasingly granted accreditation by media managers? Can sports journalism's bases of cultural authority evolve to be less dependent on access? Will sports journalism diversify and lean more towards unofficial sources as it experiences increasing alienation from the professional sports environment? The only certainty is that sports journalism's cultural authority will continue to be worth monitoring.

\section{NOTE}

${ }^{1}$ The NMC arrangement still offers little protection to journalists being banned by clubs. Since the agreement was drawn, Liverpool FC decided to completely withdraw accreditation to The Sun newspaper in February 2017 for publishing false and damaging claims about supporters' behavior during the Hillsborough disaster in 1989. Everton adopted a similar ban in April 2017 following a Sun article about one of their players, Ross Barkley.

\section{REFERENCES}

Aldridge, M. and Evetts, J. (2003) 'Rethinking the concept of professionalism: The case of journalism', British Journal of Sociology, 54 (4): 547-564.

Anderson, C. (2008) 'Journalism: Expertise, authority, and power in democratic life', in D. Hesmondhalgh (ed.) The Media and Social Theory, Abingdon: Routledge.

Anderson, C. and Schudson, M. (2009) 'News production and organisations: Professionalism, objectivity and truth seeking', in K. Wahl-Jorgensen and T. Hanitzsch (eds.) Handbook of Journalism Studies, New York: Routledge.

Banagan, R. (2011) 'The decision, a case study: Lebron James, ESPN and questions about U.S. sports journalism losing its way', Media International Australia, 140 (1): 157-167. 
Barnes, S. (2006) The Meaning of Sport, London: Short Books.

Boyle, R. (2006) Sports Journalism: Context and Issues, London: Sage.

Boyle, R. and Haynes, R. (2009) Power Play: Sport, the Media and Popular Culture.

Edinburgh: Edinburgh University Press.

Boyle, R., Rowe, D. and Whannel, G. (2009) 'Delight in trivial controversy? Questions for sports journalism', in S. Allan (ed.) The Routledge Companion to News and Journalism, London: Routledge.

Boyle, R. (2013) 'Reflections on communication and sport: On journalism and digital culture', Communication \& Sport, 1 (1/2): 88-99.

Cormode, G. and Krishnamurthy, B. (2008) 'Key differences between Web 1.0 and Web 2.0', First Monday, 13 (6). Online. Available HTTP:

<http://firstmonday.org/article/view/2125/1972> (accessed 16 March 2017).

Dart, J. (2009) 'Blogging the 2006 World Cup Finals', Sociology of Sport Journal, 26: 107-126.

Deuze, M. (2005) 'What is journalism? Professional identity and ideology of journalists reconsidered', Journalism 6 (4): 442-464.

Hamilton, D. (2007) Providing You Don't Kiss Me: 20 Years with Brian Clough, London: Harper Perennial.

Hutchins, B. and Boyle, R. (2016) 'A community of practice: Sport journalism, mobile media and institutional change', Digital Journalism. Online. Available HTTP: <

http://www.tandfonline.com/doi/abs/10.1080/21670811.2016.1234147?tab=permissions\& scroll=top $>$ (accessed 10 March 2017).

Hutchins, B. and Mikosza, J. (2010) 'The web 2.0 Olympics: Athlete blogging, social networking and policy contradictions at the 2008 Beijing Games', Convergence, 16 (3): 279297.

Hutchins, B. and Rowe, D. (2009) 'From broadcast scarcity to digital plenitude: The changing dynamics of the media sport economy', Television \& New Media, 10 (4): 354-370.

Hutchins, B. and Rowe. D. (2012) Sport Beyond Television: The Internet, Digital Media and the Rise of Networked Sport, London: Routledge.

Hytner, D. (2016) 'Arsene Wenger: West Ham have 'won the lottery' with Olympic Stadium, London: Guardian Media Group. Online. Available HTTP:

<http://www.theguardian.com/football/2016/apr/08/arsene-wenger-west-ham-olympicstadium-arsenal> (accessed 18 March 2017).

Lewis, S. (2012) 'The tension between professional control and open participation: Journalism and its boundaries', Information, Communication \& Society, 15:6: 836-866.

Lowes, M. (1999) Inside the Sports Pages: Work Routines, Professional Ideologies, and the Manufacture of Sports News, Toronto: University of Toronto Press. 
McCarthy, B. (2012) 'Consuming sports media, producing sports media: An analysis of two fan sports blogospheres', International Review for the Sociology of Sport, 48 (4): 421-434.

McCarthy, B. (2014). 'A sports journalism of their own: An investigation into the motivations, behaviours, and media attitudes of fan sports bloggers', Communication \& Sport, 2 (1): 6579.

McChesney, R. (2008) The Political Economy of Media: Enduring Issues, Emerging Dilemmas, New York: Monthly Review Press.

McEnnis, S. (2013) 'Raising our game: Effects of citizen journalism on Twitter for professional identity and working practices of British sport journalists', International Journal of Sport Communication, 6 (4): 423-433.

McEnnis, S. (2015) 'Following the action: How live bloggers are reimagining the professional ideology of sport journalism', Journalism Practice. Online. Available HTTP: <www.tandfonline.com/doi/abs/10.1080/17512786.2015.1068130> (accessed 10 March 2017).

McEnnis, S. (2016) 'Playing on the same pitch: Attitudes of sports journalists towards fan bloggers', Digital Journalism, Online. Available HTTP: < www.tandfonline.com/doi/abs/10.1080/21670811.2016.1246374> (accessed 10 March 2017).

Meltzer, K. (2009) 'The hierarchy of journalistic cultural authority: Journalists' perspectives according to news medium', Journalism Practice, 3 (1): 59-74.

News Media Coalition (2015) 'NMC clinches media deal with the Premier League', Brussels: NMC. Online Available HTTP:

<http://www.newsmediacoalition.org/news_archive/view?id=217\&x[0]=news/list> (accessed 15 March 2017).

Nicholson, M., Kerr, A. and Sherwood, M. (2015) Sport and Media: Managing the Nexus (2 ${ }^{\text {nd }}$ edition), London: Routledge.

O'Reilly, T. (2007) 'What is Web 2.0: Design patterns and business models for the next generation of software', Communications \& Strategies, 65: 17-37.

Rowe, D. (2004) Sport, Culture and the Media: The Unruly Trinity ( $2^{\text {nd }}$ edition), Buckingham: Open University Press.

Sherwood, M. and Nicholson, M. (2012) 'Web 2.0 platforms and the work of newspaper sport journalists', Journalism, 14 (7): 942-959.

Sherwood, M., Nicholson, M. and Marjoribanks, T. (2016a) 'Access, agenda building and information subsidies: Media relations in professional sport', International Review for the Sociology of Sport. Online. Available HTTP: <http://irs.sagepub.com/content/early/2016/03/18/1012690216637631.abstract> (accessed 10 March 2017). 
Sherwood, M., Nicholson, M. and Marjoribanks, T. (2016b) 'Controlling the message and the medium? The impact of sports organisations' digital and social channels on media access', Digital Journalism. Online. Available HTTP:

<http://www.tandfonline.com/doi/full/10.1080/21670811.2016.1239546?src=recsys> (accessed 10 March 2017).

Sky Sports (2015) 'Sky Sports wins Premier League video clip rights From 2016/17 season', London: BSkyB. Online. Available HTTP:

<http://www.skysports.com/football/news/11661/9920535/sky-sports-wins-premierleague-video-clip-rights> (accessed 15 March 2017).

Sports Journalists' Association (2015). 'Paper pulls out its Barnet reporter for lack of clicks', London: SJA. Online Available HTTP: <https://www.sportsjournalists.co.uk/journalismnews/regional-newspapers/paper-pulls-out-its-barnet-reporter-for-lack-of-clicks/> (accessed April 12 2017).

Steen, R. (2007) Sports Journalism: A Multimedia Primer. London: Routledge.

Sugden, J. and Tomlinson, A. (2007) 'Stories from planet football and sportsworld: Source relations and collusion in sport journalism', Journalism Practice, 1 (1): 44-61.

Sweney, M. (2015) Premier League signs deal with newspapers and agencies, London: Guardian Media Group. Online. Available HTTP:

<https://www.theguardian.com/media/2015/aug/11/premier-league-newspapers-newsagencies> (accessed 10 March 2017)

Taylor, D. (2008) This is the One: Alex Ferguson. The Uncut Story of a Football Genius, London: Aurum Press.

Tomlinson, A. (2016) 'Twitter and the rolling-news agenda on sports channels' in S. Cushion and R. Sambrook (eds.) The Future of 24-hour News: New Directions, New Challenges, New York: Peter Lang.

Turvill, W. (2015) 'Newcastle United again accused of 'gagging' media as Mirror and Sky Sports emerge as 'preferred media partners", London: Progressive Media. Available HTTP:

$<$ http://www.pressgazette.co.uk/newcastle-united-again-accused-gagging-media-mirrorand-sky-sports-emerge-preferred-media-partners/> (accessed 10 March 2017).

Waisbord, S. (2013) Reinventing Professionalism: Journalism and News in Global Perspectives. Cambridge: Polity.

Wenner, L. (1989) 'Media, sports, and society: The research agenda' in L. Wenner (ed.) Media, Sports, and Society, California: Sage.

Whannel, G. (2002) Media Sport Stars: Masculinities and Moralities, London: Routledge.

Wooldridge, I. (2007) Searching for Heroes, London: Hodder \& Stoughton.

Zelizer, B. (1992) Covering the Body: The Kennedy Assassination the Media and the Shaping of Collective Memory, Chicago: University of Chicago Press. 
Word count: 5,398 